\title{
RELATIONSHIP BETWEEN TECHNOLOGY LEADERSHIP, ICT FACILITY, COMPETENCY, COMMITMENTS AND TEACHERS PRACTICES ON IMPLEMENTATIONS WITH EFFECTIVE TEACHER'S MANAGEMENT TASKS IN SCHOOLS
}

\author{
Arumugam Raman Ph.D \\ University Utara Malaysia \\ Som Bint Shariff Ph.D \\ Institute Aminuddin Baki
}

\begin{abstract}
Information and Communication Technology (ICT) is something that is growing rapidly in a globalized era and becoming an important element in the development of an organization. Leaders play an important role in ensuring effective application of ICT in the organization, particularly in schools. Review of previous studies more engaged to the level of technology leadership and the characteristics of technological leadership practiced by leaders in the school, while the factors of a more comprehensive which include facilities for ICT, competence, and commitment of teachers in the practices of applying ICT in the management which contributes a grant impact on the management duties of teachers in schools has not been studied in Malaysia. The purpose of this study is to identify whether there is a positive relationship between technology leadership, ICT facilities, competence, commitment and practice of applying ICT teachers with effective management duties of teachers in schools using ICT. This quantitative study involves 370 teachers in secondary schools in the Kedah state which were selected randomly. Respondents gave their views on aspects of technology leadership and ICT facilities available in schools. Respondents also indicated the level of competence and commitment to apply the computer in addition to giving an opinion on the effectiveness of the application of ICT in managerial duties at the school through a questionnaire validated by experts. The findings show that there is a positive relationship between technology leadership, ICT facilities, competence and commitment of teachers to use ICT and the effectiveness of management duties of teachers using ICT in school. The role of teacher practices using ICT to be used as a moderator has a positive correlation with ICT facilities. The framework established by adopting some models related to technology leadership and Unified Theory of Acceptance and Use of Technology (UTAUT) can be used as guidelines in the application of ICT in the education system to make it more effective, particularly in systems management at school.
\end{abstract}

KEYWORDS: technology leadership, ICT facilities, competence, commitment, effectiveness of duties tract

\section{Introduction}

In Malaysia, the widespread use of ICT began with the existence of the Multimedia Super Corridor (MSC) in 1996 in line with the government's goal of making Malaysia a developed nation by 2020. In education organizations, ICT usage began in 1999 when the Ministry of Education Malaysia (KPM) introduced Bestari schools. In the initial stages of 88 schools were selected as a Pilot Project. In 2009, 50 schools in rural areas were made Rural Pilot Smart Schools. Under the plan to innovate the education system in Malaysia, the government intends to preserve all government primary and secondary schools in Malaysia by 2010. In the planning of school preservation, the 
government has devised various plans towards the preservation of school preservation. In 2012, 1BestariNet was introduced to strengthen the use of ICT in schools.

The optimum benefits of ICT integration, especially computer technology in schools, are largely dependent on the principal's sensitivity towards the development of current technology ( Ab Aziz Yusof, Norashidah Hashim \& Ooi Yeng Keat, 2004). The same opinion was also presented by Simkins (2004) and Sim (2011), efficient school leadership can determine the quality of school development and the support of the administration affects the management of technology at school. Without an important role played by principals as a technology leader in school as well as accessible ICT, the high competence and commitment of teachers will affect the implementation of every ICT innovation done at school. The study conducted by Tan (2013) in Taiwan showed that there was a positive relationship with the performance expectation (competence), business expectation (commitment), social influence (technology leadership) and ICT facilitative with the level of ICT usage in schools.

There have been numerous studies conducted on the leadership of principals and teachers in the school. The results of the study were more focused on the level of technology leadership practices implemented in schools (Yusup Hashim, 2008; Mohd Izam \& Rosnah; 2008; Sathiamoorthy Kannan, 2013; Kadela, 2002). Similar findings were obtained through the study of Aishah Tamby Omar, Sabariah Sharif, and George Tamaki (2010) at the secondary school in Kudat, Sabah to highlight some issues in the management and administration of ICT. Based on previous studies, the level of technology leadership in the school is low and medium. Most of the previous studies related to technology leadership in schools, the respondents of the study were principals who were leaders in the school. In this study, respondents are teachers who evaluate the characteristics of technology leadership practiced by principals at school. Hence the real situation in the school can be identified whether the characteristics of technology leadership that are being implemented in the school can be shared with the vision and values by teachers who play an important role as an implementing agent in the school.

\section{Literature Review}

Facilities in school are among the factors that need to be taken into account in integrating ICT in schools. According to Anderson and Dexter (2000), among the indicators that need to be present in the features of the administrator's leadership, technology are the potential to improve the ICT's facilitation in school, including providing ICT infrastructure, providing support assistance in helping to implement ICT while providing ICT skills training to teachers in school. The study conducted by Lokman Mohd Tahir (2010) on the role played by technology leaders in the school namely the principal in providing ICT facilitations at the school is still moderate level. The perfect facilitation achievement facilitates teachers to carry out management tasks using ICT.

There are also studies conducted to assess the level of competence and commitment of teachers to apply technology in teaching and learning such as the study conducted by Mohd Jasmy Abd. Rahman and RosAzura Jantan (2002), Gomathi (2003), Andre and Paul (2012). The findings from the study show that teachers' competence and commitment to apply ICT in teaching and learning in schools is still in the low and medium level. Most of the studies are more involving the use of computer technology in teaching and learning without involving the role of teachers in carrying out school management tasks which are also an important task of a teacher. This opinion is supported by a study conducted by Irfan and Nurullizam (2011) that finds the pattern of ICT research in teacher education to focus on delivery systems, learning environments and learning outcomes without involving management tasks. These management tasks are not effectively managed as a burden to teachers in schools.

Various management tasks have been carried out by teachers in schools, including data entry through the Executive Comprehensive System (SME), School Examination Analysis System (SAPS), Discipline Discipline System System (SSDM) and others. Management tasks by these teachers have become increasingly challenging as the Ministry of Education Malaysia introduced the School Based Assessment System (PBS) in 2011. This PBS system involves extensive data entry through computer use. The computer is said to be an information management tool that provides a lot of opportunities in collecting and managing various assessment data (Osman Width, 2011). Teachers feel overwhelmed with the necessary management tasks. Without the high competence and commitment of perfect teachers and facilitation will affect the implementation of every innovation done at school.

Based on this statement, it is desirable to conduct a study to find out the extent of the relationship between the level of technology leadership practices by principals, school facilitation in ICT, competence, commitment and practice 
that has been done in the teacher to apply the computer with the effectiveness of the task using ICT in schools based on evaluation and Teachers' perceptions in school. This is in line with the government's goal of improving productivity, excellence, and effectiveness in the management system using ICT. A more holistic approach involves aspects of technological leadership, ICT facilitation, teacher practice and job-effectiveness needs to be identified to transform technology into educational organizations so that implementation can be carried out more effectively.

\section{Research Objectives}

i. To identify the relationship between the technology leadership factor with the effectiveness of school management tasks Using ICT.

ii. To identify the relationship between the influence of computer technology facilitative with the effectiveness of school management tasks Using ICT.

iii. To identify the relationship between teachers' competency in using computer technology with the effectiveness of school management tasks Using ICT.

iv. To identify the relationship between teachers' commitment to apply computer technology with the effectiveness of school management tasks Using ICT.

This study does not only take into account the role factors played by technology leadership by principals, ICT facilitators as well as the competence and commitment of teachers in carrying out computer-based tasks at school but also outcomes, the effectiveness of computer-based tasks. In this study, the Unified Theory of Acceptance and Use of Technology (UTAUT) model by Venkatesh et al. (2005) has been adopted which relates to the factors that influence the attitude of teachers in applying the computer. Based on UTAUT, independent variables that play an external role (extrinsic) are the technological leadership (social influence) and the facilitation of computer technology in the school. Internal influences (intrinsic) are the influence of the users (teachers) themselves - the competence and commitment of the teachers, which are then linked to the effectiveness of the task in management at the school.

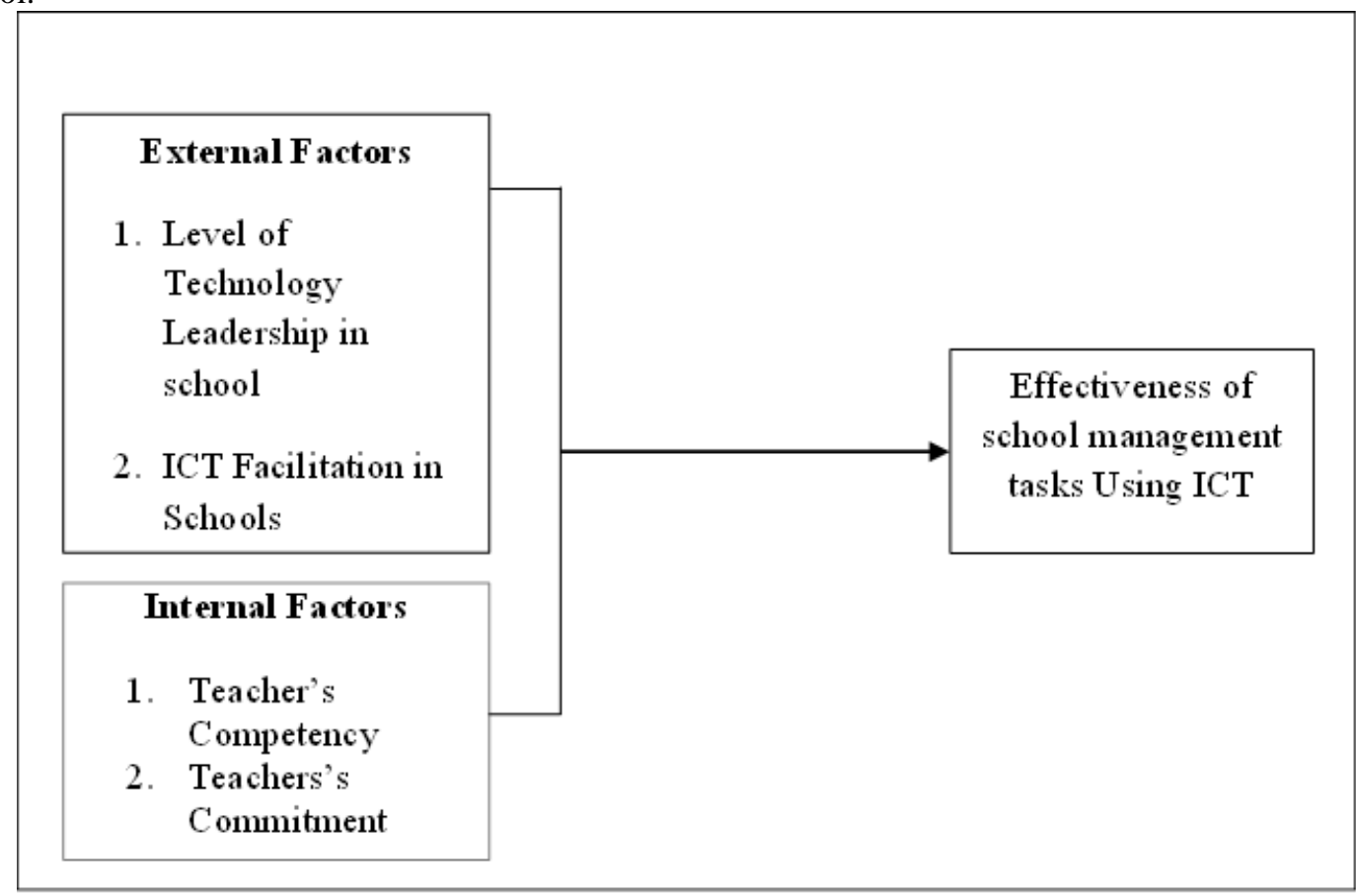

Figure 1.The study framework, the relationship between technology leadership, ICT facilitation, competence, commitment of teachers with management tasks the effectiveness of school management tasks Using ICT.

\section{Method}

The research design is used to find answers to answer questions or research problems. This study uses cross sectional design to see the relationship between the three variables. Quantitative methods were used to collect responses from respondents and studies were conducted in January 2015. Population in this study was assistant 
teachers working in Kedah. The state of Kedah is located in the northern part of Peninsular Malaysia, divided into eight districts namely Kota Setar, Kubang Pasu, Kuala Muda / Yan, Padang Terap, Pendang, Baling / Sik, Kulim / Bandar Baharu, and Langkawi.

Table 1 Number of teachers in Kedah based on gender

\begin{tabular}{llll}
\hline Gender & Male & Female & Total \\
\hline NumberofTeachers & $4,013(34 \%)$ & $7,941(66 \%)$ & $11,954(100 \%)$ \\
& & & \\
Sample & $124(34 \%)$ & $246(66 \%)$ & $370(100 \%)$ \\
\hline
\end{tabular}

\section{Research Instruments}

Instrument is a measuring tool used to provide the information needed to understand the variables studied. In research, instrumentation processes include not only the selection and design of instruments but also the procedures and conditions in which the instances are governed. In this study, several existing instruments relating to technology leadership based on the characteristics constructed by ISTE in NEST-A have been altered in addition to other instruments constructed based on the TAM model and perceptual instruments on the effectiveness of the modified PTJE tasks that have been used.

Table 2The distribution of research instrument instruments

\begin{tabular}{|c|c|c|c|}
\hline Variable & Dimension & Resource & Total \\
\hline & Section A & Demography & 8 \\
\hline \multirow{6}{*}{$\begin{array}{l}\text { IndependentVaria } \\
\text { ble }\end{array}$} & Section B & & \\
\hline & & NationalEducationalTechnology & 12 \\
\hline & I.TechnologyLeadership in Schools & $\begin{array}{l}\text { Standard for Administrator (NETS- } \\
\text { A) }\end{array}$ & \\
\hline & II. ICT Facilitation in Schools & $\begin{array}{l}\text { UnifiedTheoryofAcceptanceandUseo } \\
\text { fTechnology (UTAUT) }\end{array}$ & 8 \\
\hline & III. TeacherCompetence & $\begin{array}{l}\text { PerceptionofTechnologyonJobEffect } \\
\text { iveness(PTJE) }\end{array}$ & 8 \\
\hline & IV.Teachers' Commitment & $\begin{array}{l}\text { UnifiedTheoryofAcceptanceandUseo } \\
\text { fTechnology (UTAUT) }\end{array}$ & 7 \\
\hline \multirow[t]{2}{*}{$\begin{array}{l}\text { DependentVariabl } \\
\mathrm{e}\end{array}$} & $\begin{array}{l}\text { Section } \mathbf{C} \\
\text { Theeffectivenessofschoolmanagem } \\
\text { enttasksUsing ICT. }\end{array}$ & $\begin{array}{l}\text { PerceptionofTechnologyonJobEffect } \\
\text { iveness(PTJE) }\end{array}$ & 4 \\
\hline & & Total & 47 \\
\hline
\end{tabular}

The pilot study was conducted to evaluate the reliability of which is done through an analysis of SPSS version 17.0 Alpha Cronbach's values for each dimension are as follows:

Table 3Cronbach's Alpha value for each dimension

\begin{tabular}{ll}
\hline Dimension & CronbachAlpha \\
\hline Technologyleadership InSchool & 0.890 \\
Facilitation & 0.896 \\
Competence & 0.820 \\
Commitment & 0.709 \\
TheeffectivenessofschoolmanagementtasksUsing ICT. & 0.786
\end{tabular}




\section{Smart PLS Data Analysis}

This study was conducted using primary data. The data collected then analyzed using Partial Least Square (PLS) was first developed by Herman Wold (1982).

\section{Reliability Indicator}

Reliability indicators can be specified as the value for the outer model or model of the relationship between the indicator measuring the constructs. The indicator reliability level is said to be high when the loading value with construct> 0.7. However, for exploratory studies the value of loading $>0.6$ is sufficient (Hair et al., 2014). For loading values $<0.6$ it is necessary to refine the data which is to drop the indicator to improve the level of reliability of the assessed indicators. After the cleaning indicators that are $>0.6$ used in this study as shown in the following Table 4.

Table 4Indicator reliability (Indicator reliability) after cleaning

\begin{tabular}{|c|c|c|c|c|c|}
\hline & ICT Facilitation & Technologyleadership & $\begin{array}{l}\text { Teachers' } \\
\text { Commitment }\end{array}$ & $\begin{array}{l}\text { Teachers' } \\
\text { Competency }\end{array}$ & Effectiveness \\
\hline FC1 & 0.779 & & & & \\
\hline FC2 & 0.837 & & & & \\
\hline FC3 & 0.791 & & & & \\
\hline FC4 & 0.815 & & & & \\
\hline FC5 & 0.829 & & & & \\
\hline FC6 & 0.797 & & & & \\
\hline FC7 & 0.820 & & & & \\
\hline FC8 & 0.690 & & & & \\
\hline KMT1 & & & 0.692 & & \\
\hline KMT2 & & & 0.762 & & \\
\hline KMT3 & & & 0.795 & & \\
\hline KMT4 & & & 0.687 & & \\
\hline KMT6 & & & 0.731 & & \\
\hline KMT7 & & & 0.713 & & \\
\hline KPT1 & & & & 0.744 & \\
\hline KPT2 & & & & 0.788 & \\
\hline КРT3 & & & & 0.825 & \\
\hline KPT5 & & & & 0.756 & \\
\hline KPT7 & & & & 0.727 & \\
\hline KT1 & & 0.686 & & & \\
\hline KT11 & & 0.763 & & & \\
\hline KT12 & & 0.768 & & & \\
\hline KT2 & & 0.815 & & & \\
\hline KT3 & & 0.712 & & & \\
\hline KT4 & & 0.730 & & & \\
\hline KT6 & & 0.708 & & & \\
\hline KT7 & & 0.699 & & & \\
\hline KT8 & & 0.759 & & & \\
\hline KT9 & & 0.784 & & & \\
\hline TGS1 & & & & & 0.659 \\
\hline TGS10 & & & & & 0.694 \\
\hline TGS11 & & & & & 0.732 \\
\hline TGS12 & & & & & 0.744 \\
\hline TGS13 & & & & & 0.780 \\
\hline TGS15 & & & & & 0.741 \\
\hline
\end{tabular}




\begin{tabular}{ll}
\hline TGS2 & 0.688 \\
TGS3 & 0.732 \\
TGS7 & 0.657 \\
TGS9 & 0.695 \\
\hline
\end{tabular}

\section{Composite Reliability (Composite Reliability)}

Reliability composite (Composite reliability) is a measure of internal consistency reliability and construct a measure can be assessed based on two types of measure that are internal consistency and Cronbach Alpha (Ghozali, 2006). Anyhow unlike composite reliability, Cronbach Alpha makes the same assumption in a loading indicator. In the context of smart PLS, composite reliability is better recognized and suited to more appropriate reliability criteria.

Table 5 Computability reliability findings

\begin{tabular}{ll}
\hline & CompositeReliability \\
\hline School ICT Facilitation & 0.932 \\
TechnologyLeadership & 0.925 \\
Teachers' Commitment & 0.873 \\
TeacherCompetence & 0.878 \\
Effectiveness & 0.912 \\
\hline
\end{tabular}

Based on Table 5, the reliability value of the overall composite construct, the lowest value is 0.873 for the teacher's commitment and the highest is 0.932 for the ICT facilitation in the school. The recommended value of composite reliability for exploratory type studies is $>0.60$ while for theory validation is $>0.70$ (Chin, 1998; Laten and Ghozali, 2012: Hair, 2014). From the findings, it shows that the value of its reliability is acceptable, especially for this research

\section{Convergent validity}

Discriminant validity of the measurement model with reflective indicators was assessed by measurement of c ross loading constructs. If the construct correlation with the item of measurement is greater than the other constructs measure, then it indicates that latent constructs show a better value finding than others. In this study convergent validity is established.

\section{Discriminant validity}

If the AVE of each construct is larger than the correlation between the construct with other constructs then said to have the good discriminant validity. These measurements can be used to measure the latent variable component score reliability and the results are more conservative than the composite reliability. According to Fornnel and Larcker, 1981 (Ghozali, 2006), values for average variance extracted (AVE) need>0.50. The value of AVE for each construct exceeds 0.50 , reflecting that the constructs of the study have met the convergent validity criteria (Barclay et al., 1995; Fornell \& Larcker, 1981; Henseler et al., 2009). In addition, the value of the AVE (AVE AVE) value shown in diagonal is greater than the correlation between the other constructs shown non-diagonal. This shows that the results of this analysis have reached the discretionary set of validity test criteria (Henseler et al., 2009, Yang, 2009).

Table 6 The AVE findings from the data in the smart PLS analysis

\begin{tabular}{lc}
\hline & $\boldsymbol{A} \boldsymbol{V E}$ \\
\hline School ICT Facilitation & 0.633 \\
TechnologyLeadership & 0.553 \\
Teachers' Commitment & 0.534 \\
TeacherCompetence & 0.591 \\
Effectiveness & 0.509 \\
\hline
\end{tabular}

Table 6 shows the results of the testing of factors for each study construct. The factor load factor for each item is greater than 0.5 , indicating that items for each construct have reached the standard of validity and reliability analysis set (Chin, 1998; Fornell \& Larcker, 1981; Gefen \& Straub, 2005). 


\section{Fornel Larcker Criterion}

Fornel Larcker Criterion validity is the measurement of discriminant (discriminant validity) comparing the square root of the average variance extracted for each construct correlation with all other constructs in the model.

Table 7 Fornel Larcker Criterion

\begin{tabular}{llllll}
\hline & $\begin{array}{l}\text { ICT } \\
\text { Facilitation }\end{array}$ & $\begin{array}{l}\text { Technologyl } \\
\text { eadership }\end{array}$ & $\begin{array}{l}\text { Teachers' } \\
\text { Commitment }\end{array}$ & $\begin{array}{l}\text { Teachers' } \\
\text { Competency }\end{array}$ & Effectiveness \\
\hline School ICT Facilitation & 0.796 & & & & \\
Technology Leadership & 0.566 & 0.743 & & & \\
Teachers' Commitment & 0.217 & 0.327 & 0.731 & 0.769 & 0.713 \\
Teacher Competence & 0.297 & 0.424 & 0.516 & 0.567 & 0.493 \\
Effectiveness & 0.441 & 0.610 & 0.493 & \\
\hline
\end{tabular}

Table 7, explains that the latent variable technology leadership found the AVE is 0.566 and the power of two is 0.743, the AVE commitment Guru 0217 and the power of two is 0.743, the AVE competence Guru 0297 and the squared 0769 onwards the AVE perception 0.441 and squares Is 0.713. From this findings, all AVE values for each variable latent are lower than the square values of each variable. Therefore this finding indicates the discriminant validity is strong (Ken Wong Kwong\& Kay, 2013).

\section{Estimate for Path Coefficients}

The estimate for path model in this study was purified by drop indicator value $<0.60$ for each construct. Fillers are made to reinforce every construct in the model. The estimate for the path coefficients, which represent the path coefficients The magnitude of the relationship or influence of latent construction. It was done with the bootsrapping procedure.

Table 8Estimate for path coefficients

\begin{tabular}{|c|c|c|c|c|c|}
\hline & $\begin{array}{l}\text { ICT } \\
\text { Facilitation } \\
\end{array}$ & $\begin{array}{l}\text { Technologyl } \\
\text { eadership }\end{array}$ & $\begin{array}{l}\text { Teachers' } \\
\text { Commitment }\end{array}$ & $\begin{array}{l}\text { Teachers' } \\
\text { Competency }\end{array}$ & Effectiveness \\
\hline School ICT Facilitation & & & & & 0.109 \\
\hline Technology Leadership & & & & & 0.364 \\
\hline Teachers' Commitment & & & & & 0.210 \\
\hline Teacher Competence & & & & & .273 \\
\hline
\end{tabular}

Refer to Table 8it can deduce that the value of path coefficients for facilitation ICT in schools is $0.109,0.364$ for technology leadership, teachers 'commitment is 0.210 , and 0.273 teachers' competence.

\section{Coefficient of determination ( $R^{2}$ Ratings)}

Rating of $\mathrm{R}^{2}$ is the number of variants that describe endogenous latent variables in a model of a relationship model. For example, the $\mathrm{R}^{2}$ will describe the percentage change in the latent variable endogenous in conjunction with an exogenous latent variable. The value of $R^{2}=0.67$ categorized as robust, $R^{2}=0.33$ are classified as medium and $R^{2}=$ 0.19 is classified as poor (Chin, 1998; $\mathrm{h}$

Hanseleret. al., 2009). $\mathrm{R}^{2}$ values were analyzed through SmartPLS in this study, is 0528 . $\mathrm{R}^{2}$ findings on the effectiveness of management tasks by teachers using ICT 0528 is classified in the moderate level.

Table 9 Hypothesis Testing

\begin{tabular}{lllll}
\hline Hypothesis & Relationship & $\begin{array}{l}\text { Coefficien } \\
\boldsymbol{t}(\boldsymbol{\beta})\end{array}$ & $\boldsymbol{t}$ value & Result \\
\hline$H_{1}$ & Technologyleadership -> Effectiveness & 0.364 & 8.127 & $0.000^{*}$ \\
$H_{2}$ & Facilitation $\rightarrow$ Effectiveness & 0.109 & 2.515 & $0.012^{*}$ \\
$H_{3}$ & Commitment->Effectiveness & 0.210 & 3.650 & $0.000^{*}$ \\
$H_{4}$ & Competency $\rightarrow$ Effectiveness & 0.273 & 6.065 & $0.000^{*}$ \\
\hline
\end{tabular}

The findings from the analysis of the study using the smart PLS show that there is a significant relationship between the leadership of technology by principals in school and the effectiveness of teacher-management tasks using 
computers in management tasks. This finding is in line with the findings of Chang, et al. (2008) which studies on 1,880 teachers in primary schools in Taiwan found that professors who practice high technology leadership qualities can enhance effective ICT integration. Nordin and Norazah (2010) examine how far three dimensions of technology are vision and leadership, learning and teaching and professional practice and gender differences. The findings show that the principals' leadership level in the school is moderate. Findings in terms of gender differences show no significant difference. Hence, it can be concluded that leadership of technology leaders in the country is at a moderate level resulting in the effectiveness of ICT utilization as well as moderate.

The Importance of Technology Leadership with the Effectiveness of Teacher's Assignments Using Computers This finding demonstrates that leadership factors play an important role in bringing to every innovation implemented in schools including ICT implementation, especially computers at school. Based on the Role Model, Responsibility and Objectives of ICT Integration by Flanagan and Jacobson (2003), leaders play an important role in determining the effectiveness of ICT integration in schools. School leaders play a role in leading the school community, including teachers, students, and staff in implementing ICT implementation can be implemented effectively either in learning and teaching or management systems in schools.

Based on the Flanagen and Jacobsen (2003) models, the effectiveness of ICT integration also includes equality of assumptions, vision visions, ubiquitous networks and professional development effectiveness. The equality of assists involves the ICT facilitation available in the school, the ICT infrastructure provided beside its level of applicability. School leaders also play an effective professional development. With effective professional development teachers' competence will enhance the implementing of ICT.

The findings of the study on leadership roles in significant ICT integration with the effectiveness of this task are also in line with the Leadership Anderson and Dexter (2005) models. This model contains eight indicators on technology leadership that provides effective integration of technology either involving ICT integration in teaching and learning as well as management systems in schools. Among the outcomes of this model are teachers integrating ICT in school. The role of school leaders is crucial in determining the effectiveness of teacher management tasks using ICT in schools.

Another ICT integration model that emphasizes the role of school leaders is the model introduced by ISTE, NESTA. NEST-A outlines some of the roles that school leaders should play to ensure the effectiveness of ICT implementation at school. Therefore, the findings of this study show that school leaders as technology leaders are significant with the effectiveness of ICT use in school management systems. This finding is also consistent with the findings of the previous study. Among them is the study of Chang, et al (2008) which is the leadership of a school that practices high-tech leadership features can enhance effective ICT integration. The findings are also in line with the findings of Chang, HI (2012) that there is a significant relationship between technology leadership and teacher's computer literacy and teaching effectiveness. However, this study focuses on the effectiveness of teacher duties in the school management system.

The conclusion can be said that school leaders play an important role in ICT integration in schools. Leadership that practices high technology leadership features will have a positive impact on the effectiveness of ICT integration within the organization. The findings show that there is a significant relationship between technology leadership and the perception of the effectiveness of teacher management tasks in school.

\section{References}

[1] Ab. Aziz Yusuf, NorashidahHashim, \&OoiYengKeat. (2004). Introduction to management. Kuala Lumpur: Prentice Hall Pearson Malaysia.

[2] AishahTamby Omar, Sabariah Sharif, \& George Tamaki, (2010).Leadership leadership and teacher competence towards the integration of information technology in teaching in the Kudat district school. Journal of Teacher Education Research, 5, 120-145.

[3] Almalki, G., Williams, N. (2012). A strategy to improve the usage of ICT in the Kingdom of Saudi Arabia primary school. International Journal of Advanced Computer Science and Applications, 3 (10), 201242 | P age www.ijacsa.thesai.org

[4] Baron, RM, \& Kenny, DA (1986). The mooderator mediator variable distinction in social psychological research: Concepptual, straregic, and statistiacal considerations. Journal of Personality and Social Psychology, 51, 1173-1182.

[5] Blackwell, JM (2009). Middle school principal $€$ тM $\mathrm{s}$ perceptions of the effect of technology on job effectiveness.(Dissertation Ed.D. Marshall University: Huntington, West Virginia 
[6] Chang, I.-H., Chin, JM, \& Hsu, C.-M.(2008). Teachersâ $€$ TM perceptions of the dimensions and implementation of technology leadership of principals in Taiwanese elementary Schools.Educational Technology \& Society, 11 (4), 229A $€ " 245$.

[7] Creswell, JW (2005). Educational research: Planning, conducting, and evaluating quantitative and qualitative research (2nd ed.). Pearson Merrill Prentice Hall: New Jersey.

[8] Davis, FD, \&Venkatesh, V. (1996). A critical assessment of potential biases in the measurement technology acceptance model: Three experiments .International Journal of Human-Computer Studies, 45, 19a € "45.

[9] Diez, E., \&Mcintosh, BS (2009).A review of the factors which influence the use and usefulness of information systems. Journal of Environmental Modeling \&Software , 24, 588-602.

[10] Ministry of Education, (2011). Preliminary Report Malaysia Education Blueprint 2013-2025 . Putra Jaya: Ministry of Education.

[11] Osman width. (2011). Action Research in Education: Theory and Practice . UPSI, TanjungMalim.

[12] Palaigeorgiou, GE, Siozos, PD, Konstantakis, NI \&Tsoukalas, IA (2005). A computer attitudes scale for computer science freshmen and its educational implications. Journal of ComputerAssistedLearning , 21 , 330-342.

[13] Rosnaini Mahmud, Mohd Arif Hj. Jalaluddin Ismail and Ibrahim. (2011). The level of ICT skills and integration among smart school teacher. Journal of Technology Education , 1 (1).

[14] SharifahNorPuteh\&KamarulAzman $\quad$ Abd $\quad$ Salam. $\quad$ (2011). ICT Tahapkesediaanpenggunaandalampengajarandankesannyaterhadaphasilkerjadantingkahlakumuridprasekolah .JurnalPendidikan Malaysia, 36 ( 1) .25-34.

[15] Sim, QC (2011). Instructional leadership among prinscipal of secondary schools in Malaysia. Educational Research , 2 (12), 1784-1800.

[16] Simkins, T. (2004). Leadership in education: What works' or what makes sense ?. Sheffield: Sheffield Hallam University.

[17] Turban, E. \& Aronson, JE (2007). Decision support systems and intelligence system s. USA: Prentice Hall International.

[18] Vanderlinde R., R. Hermans\& Van BJ (2010). ICT research and school performance feedback: a perfect marriage ?. Educational Studies, 36, 341â € "344.

[19] Vanderlinde R., Van BJ \&Hermans R. (2009). Educational technology on a turning point: curriculum implementation in Flanders and challenges for schools. EducationalTechnology Research \& Development, 57, 573â € "584.

[20] Venkatesh, V., \& Davis, FD (1996). A model of the antecedents of perceived ease of use: Development and test . Decision Sciences , 27 (3), 451 â $€ " 481$.

[21] Venkatesh, V., \& Davis, FD (1996). A model of the antecedents of perceived ease of use: Development and test . Decision Sciences , 27 (3), 451â € "481.

[22] Venkatesh, V., Morris, MG, Davis, FD, \& Davis, GB (2003). User Acceptance of Information Technology: Toward a Unified View, MIS Quarterly, 27 , 425-478.

[23] Venkatesh, V., Morris, MG, Davis, FD, \& Davis, GB (2003). User Acceptance of Information Technology: Toward a Unified View, MIS Quarterly, 27 , 425-478.

[24] ZaidatunTasir, Kawla Mohammed Noor Dayana Abd. Halim \&Jamalluddin Aaron. (2012). Relation between teachers' ICT competency, confidence level, and satisfaction toward training proggrammes: A case study for postgraduate students. The Turkish Online Journal of Education Technology, 11 (1), 138-144. 